\title{
ANÁLISIS DE ERRORES CONCEPTUALES EN GEOLOGÍA A PARTIR DE LAS EXPRESIONES GRÁFICAS DE LOS ESTUDIANTES
}

\author{
LILLO BEVIÁ, J. \\ Departamento Didácticas Especiais. Universidade de Vigo.
}

\begin{abstract}
SUMMARY
Detection of misconceptions by pupil's drawings permits us to have evidence of some misconceptions wich would have gone unnoticed interpreting only their vocal or writing expressions. Investigation on fossil and fossilisation, internal structure of the Earth, origin of mountains and others, reinforces the previous affirmation and permits us to recommend the non-utilisation of sequential drawings containing high conceptual charge, in order to simplify complex geological processes, because that simplification generates new misconceptions.
\end{abstract}

\section{INTRODUCCIÓN}

El presente trabajo se enmarca en el proyecto de investigación XUGA37202A91 financiado por la Xunta de Galicia en orden a investigar la percepción espacial y temporal de los alumnos de educación infantil, primaria y secundaria desde la perspectiva integrada de varias áreas de conocimiento. En el área de ciencias de la Tierra orientamos nuestras investigaciones dentro deI subproyecto Construir la geología.

\section{METODOLOGÍA}

Utilizamos preguntas abiertas que insisten en la expresión gráfica de los conceptos y analizamos los dibujos obtenidos agrupándolos por los conceptos que expresan los alumnos.

Las preguntas aquí comentadas forman parte de una encuesta que se pasó a alumnos de 10 a 15 años en centros de ensenanza primaria de la provincia de Pontevedra, refiriéndose esta comunicación a algunos aspectos resaltados al formular las preguntas que se indican a continuación. ( El análisis más detallado de los aspectos de las encuestas sobre los temas indicados puede consultarse en las obras del autor citadas en las referencias bibliográficas).

\section{Preguntas}

1. Haz un dibujo de cómo crees que es la Tierra por dentro y pon nombre a sus partes.

2. ¿Cómo crees que se forman las montañas? Explica tus ideas y utiliza dibujos para exponerlas.

3. Explica valiéndote de dibujos y el menor texto posible cómo se han podido formar los tipos de rocas que conoces.

4. Explica mediante dibujos cómo crees que se ha formado un fósil.

\section{ANÁLISIS DELOS RESULTADOSOBTENIDOS}

Los dibujos de las táminas que siguen van identificados por letras y un número final. Este último se refiere al número que ocupa el alumno en ese grupo. Las Ietras indican a los grupos y edades siguientes: para la lámina I: $\mathrm{Al}, \mathrm{B} 1=5^{\circ}(10-11$ años $), \mathrm{Cl}, \mathrm{DI}, \mathrm{EI}=6^{\circ}(11-12$ años), $\mathrm{A} 2, \mathrm{~B} 2=7^{\circ}$ (12-13 años), C2, D2, E2, F2 $=8^{\circ}$ (1314); para el resto de las láminas: $\mathrm{A}, \mathrm{B}, \mathrm{C}=8^{\circ}, \mathrm{D}=7^{\circ}$, $\mathrm{E}=6^{\circ}, \mathrm{F}=5^{\circ}$. 


\section{Sobre la estructura interna de la Tierra (Lámina 1)}

1.1. La mayoría de los alumnos considera la Tierra dividida en tres capas concéntricas (CI-10), aumentando el número de capas hacia cursos superiores (A2-2). Es de notar que en ningún caso expresan proporcionalidad o escala sobre el espesor de las capas y que siempre aparece la corteza sobre la astenosfera, persistiendo la confusión corteza y litosfera. La astenosfera la dibujan siempre sobre el manto superior y no como una parte del mismo (A2-2 y A2-1). Persiste el empleo de términos confusos como sial y sima (D2-7), no siendo este error imputable a los alumnos sino a los libros de texto y profesores que los emplean sin actualización científica.

1.2. Es muy frecuente considerar un núcleo caliente y fundido (D1-2), que para muchos es la fuente de los magmas volcánicos (D1-4). Este esquema lo reproducen también mis alumnos de $3^{\circ}$ de Magisterio.

1.3. Las representaciones en dos dimensiones en forma de sector circular o planas rectangulares son también frecuentes. El sector circular lo emplean más en cursos superiores (A2-1).

Existen intentos de reproducir la estructura tridimensional que aparece en muchos libros de texto (C1-23, E2-10), pero fallan en el intento por no tener adquirida la percepción del espacio en tres dimensiones. De todos los alumnos encuestados solamente uno consiguió una aproximación a la expresión en tres dimensiones.

1.4. En cursos inferiores $\left(5^{\circ}\right.$ y a veces $\left.6^{\circ}\right)$ perduran las influencias de películas y novelas fantásticas, especialmente Viaje al centro de la Tierra de Julio Verne, y representan cavidades con agua, lava (B1-2) apuntando Ia posibilidad de la existencia de ciudades subterráneas (B1-8). Esta tendencia a la creeencia en fantasías desaparece claramente en $7^{\circ}$ y $8^{\circ}$.

1.5. Un quinto grupo podría formarse con expresiones no esperadas como la C1-4 con una representación en forma de dedo y el núcleo en la parte alta, o la E1-6, que confunde la disposición de capas internas de la Tierra con la disposición zonal de paralelos y meridianos. Es evidente que subsiste una falta de la percepción tridimensional que se traduce en fallos en su representación.

\section{Sobre el origen de las montañas (La lámina 2 expresa las ideas fundamentales en forma de dibujos secuenciales)}

2.1. El choque de placas tiene connotaciones lingüísticas que introducen errores conceptuales en geología (D-11). Lo que ocurre en el choque de las placas es un misterio para los alumnos y algunos simplifican el proceso por la forma resultante (A-3). Otros resuelven el interrogante del choque de forma lógica para ellos, cabalgando las placas (A-8). Está claro, para ellos, que las placas al chocar se elevan (D-11) o cabalgan (A-8).

2.2. La aplicación de fuerzas horizontales opuestas es también un mecanismo fácilmente asimilado por los alumnos (B-26), pero lógicamente interpretan la montaña como forma resultante, pasándoles desapercibida la complejidad del proceso orogénico.

2.3. Otro gran porcentaje de alumnos aduce el mecanismo volcánico para explícar el origen de las montañas. La montaña es la lava acumulada y enfriada (F-24).

2.4. La teoría del arrugamiento de la corteza terrestre por enfriamiento (E-21) aporta también un mecanismo lógico e intuitivo para estas edades.

2.5. La erosión es otro mecanismo ampliamente aceptado (A-17). La montaña es la forma resuitante de la erosión de la tluvia principalmente.

2.6. En el extremo lógicamente opuesto surgen las montañas como resultado de la acumulación de sedimentos (D-19).

\section{Sobre el origen de las rocas (Lámina 3)}

Destacamos solamente el origen sedimentario y volcánico, ya que los orígenes plutónico y metamórfico pasan desapercibidos para los alumnos de estas edades.

3.1. Origen sedimentario: El viento transporta las partículas que al acumularse en otro lugar forman las rocas por sedimentación (A-26) o bien mediante erosión, transporte y sedimentación (D-1). El paso de sedimento a roca es un proceso que les pasa siempre desapercibido.

3.2. Origen volcánico (D-27): Es el que mejor identifican.

\section{Sobre el origen de los fósiles (Lámina 3)}

4.1. El error más difundido consiste en identificar fósil con resto orgánico, sea éste concha o esqueleto (A-27).

4.2. Las impresiones de peces y hojas en las rocas se interpretan "por morir el animal pegado a la roca» (A-25) o por quedar la hoja «incrustada» en la piedra (A-38).

4.3. Son menos numerosos los dibujos secuenciales que incluyen el enterramiento en el proceso de fosilización (F-20), y aun así ningún alumno percibe las transformaciones que ocurren después del enterramiento hasta que se forma el fósit.

\section{CONCLUSIONES}

1. Las interpretaciones de dibujos y especialmente de secuencias de dibujos permite poner en evidencia la aparición de errores conceptuales no sospechados por el profesor cuando obtiene respuestas orales.

2. Mantenemos la tesis de que no es prudente emplear en ciertas edades dibujos secuenciales que encierren gran 


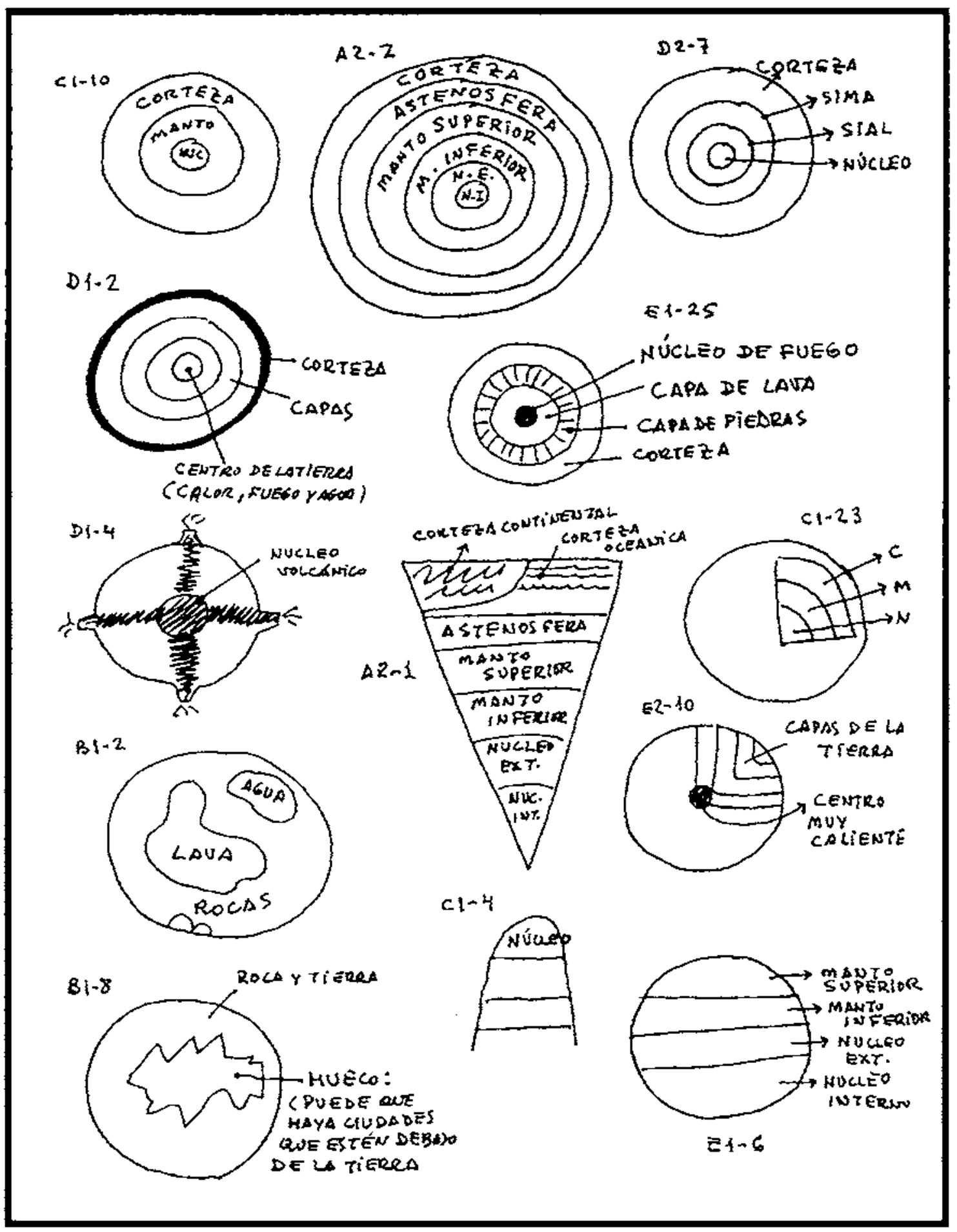

carga conceptual porque dan lugar a falsas concepciones en lugar de producir el concepto esperado.

Frecuentemente se producen entrecruzamientos de imágenes complejas o de difícil comprensión como pueden ser las secuencias sedimentarias del origen del carbón o del petróleo, la formación de arrecifes, el origen del Sistema Solar o de la Tierra, que frecuentemente se explican en libros y enciclopedias en forma de secuencias, queriendo hacer así más asequibles los conceptos. 


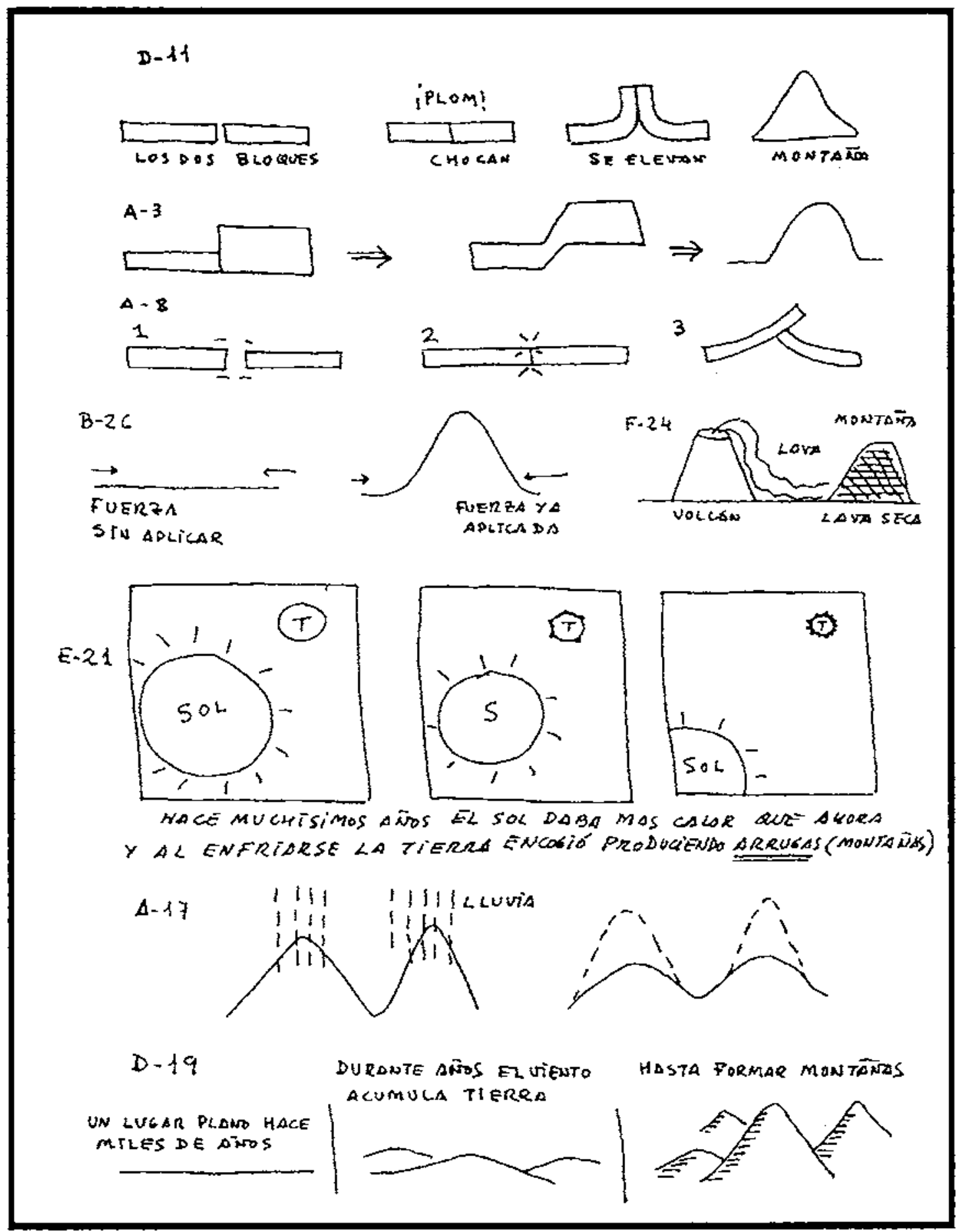

Estos dibujos simplificados en la mente del autor adulto que los diseña no producen el efecto simplicador deseado sino que introducen nuevos errores por la carga conceptual que encierran. 


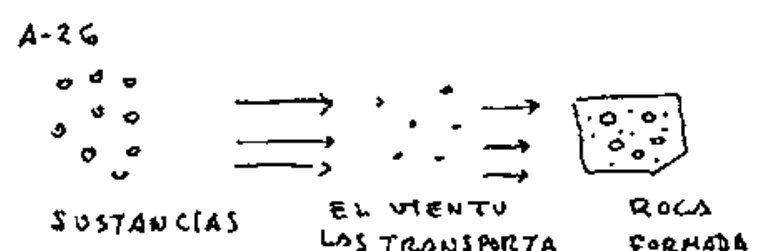

$D-1$

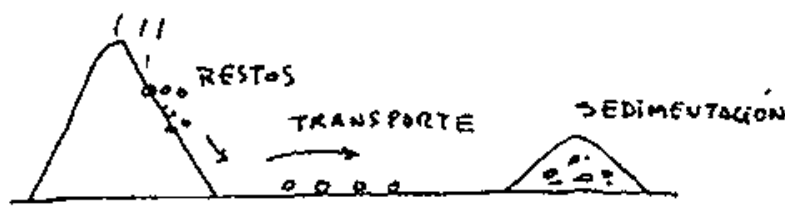

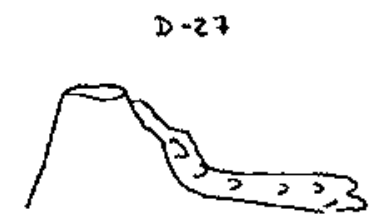

CON LA LAVA

DE LOS VOLCAAES
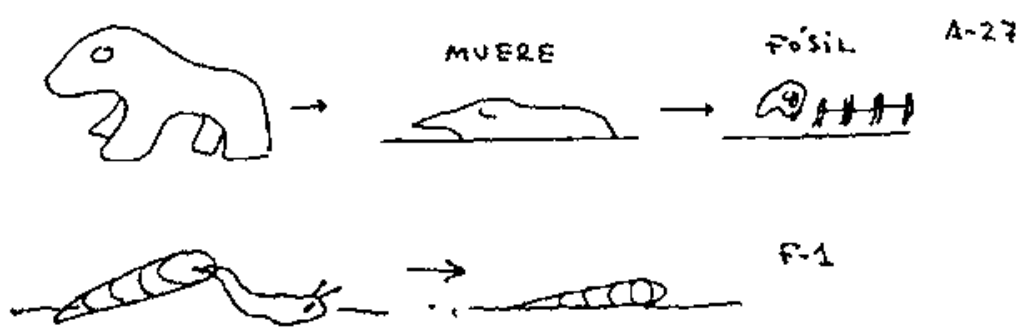

$F-1$
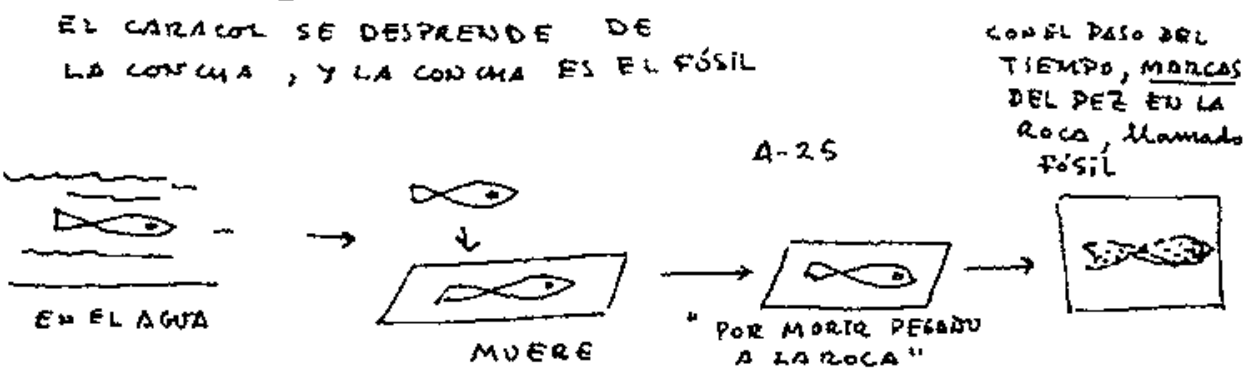

$4 \cdot 38$

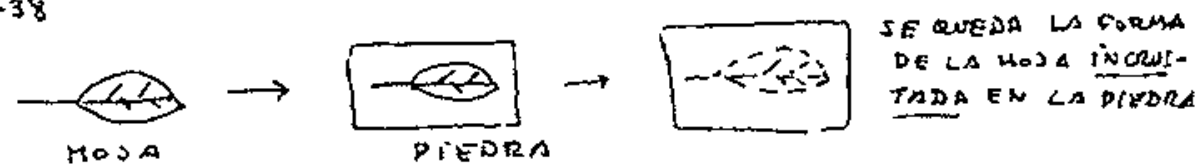

920
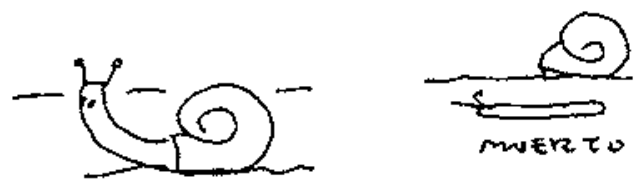

(C) SADO

\section{REFERENCIAS BIBLIOGRÁFICAS}

ASTOLFI, J.P., 1987: Les representations des élèves en situation de classe, Revue Française de Pédagogie, 45, pp. 126-128.

CARMICHAEL, P., DRIVER, R., HOLDING, B., PHILLIPS, I., TWIGGWR, D. y WATTS, M., 1990. Research on student's conceptions in Science: a biblingraphy. Children's
Learning in Science Research Group. CSSME, University of Leeds.

DRIVER, R., GUESNE, E. y TIBERGHIEN, A., 1989. Las ideas científicas en la infancia y la adolescencia. (Morata: Madrid). 
GRANDA, A., 1988. Esquemas conceptuales previos de los alumnos en geología, Enseñanza de las Ciencias, 6(3), pp. 239-243.

HAPPS, I.C., 1984.The utility of alternative knowledge fromeworks in effecting conceptual change: some examples from the Earth Sciences. D. Phill. Thesis. Unpublished. (University of Waikato: Hamilion, Nueva Zelanda).

LILLO, J., 1992a. Sugerencias sobre laenseñanza de los conceptos mineral y roca en la enseñanza Primaria y Secundaria.

LILLO, I., 1992b. Representaciones de los alumnos de EGB sobre los conceptos mineral y roca.

LILLO, J., 1992c. Análisis de las representaciones de los alumnos de EGB sobre la estructura interna de la tierra, Boletin das ciencias, 13(5), pp. 76-84.

LILLO, J., 1992d. Representaciones de los alumnos de EGB sobre los conceptos fósil y fosilización. Congreso Intemacional sobre "Las didácticas específicas en la formación del Profesoradon, Santiago, julio del 92 (en prensa).

LILLO, I., 1992e. Representaciones de los alumnos de EGB sobre el origen de las rocas. Congreso Internacional sobre "Las didácticas específicas en la formación del profesorado", Santiago, julio del 92 (en prensa).

OSBORNE, R. y FREYBERG, P.,1991. El aprendizaje de las ciencias. Implicaciones de la ciencia de los alumnos. (Narcea: Madrid).

PFUNDT, H. y DUIT, R., 1988. Bibliography. Students Altemative Frameworks and Science Education, $2^{\circ}$ ed. (Institut for Science Education: Kiel).

SCHOON, K.J., 1992. Sudent's alternative conceptions of Earth and Space, Journal of Geological Education, 40, pp. 209-214. 